\title{
Principles for Successful Cognitive Interventions
}

\author{
Robert Pasnak \\ Correspondence: Robert Pasnak, Department of Psychology, George Mason University, USA.
}

Received: November 3, 2019

doi:10.11114/jets.v7i12.4599

\author{
Accepted: November 24, 2019 Online Published: November 27, 2019 \\ URL: https://doi.org/10.11114/jets.v7i12.4599
}

The preparation of this paper was supported by the Institute of Education Sciences, U.S. Department of Education, through Grant 305A170114 to George Mason University. The opinions expressed are those of the authors and do not represent views of the Institute or the U.S. Department of Education

\begin{abstract}
This essay is a distillations of decades of efforts at cognitive intervention by many educators. Three likely outcomes for cognitive interventions are described. Recommendations for when interventions scan most effectively be conducted, and what children are most likely to respond most favorably are also advanced. Finally, the general nature of the subject matter of successful cognitive interventions, and parameters that are most likely to produce good internalization and application of whatever is conveyed by the intervention are also described.
\end{abstract}

Keywords: cognition, intervention, thinking

\section{Introduction}

Devising procedures for improving the cognitive abilities of children, as opposed to teaching them academic subject matter directly, has frequently been a goal for educational programs. These may be directed at children individually, or may be part of a curriculum for all children. The line between a cognitive intervention and an instructional innovation is blurred, bur the expectation in the former is that improving the children's thinking may benefit them in many educational activities. Thus, the definition of a cognitive intervention is that its content is designed to improve cognitive abilities rather than to improve academic abilities of some specific sort, e. g. reading, written language, or mathematics. The assumption basic to efforts at cognitive intervention is that the hoped for improvement in cognitive abilities will lead to subsequent improvement in academic achievement, because the students are better able to understand their teacher's instruction.

Examples of cognitive interventions are programs directed at preschoolers, such as High/Scope (Weikart, Rogers, Adcock, \& McClelland, 1971; Berrueta, Schweinhart, Barnett, Epstein, \& Weikart, 1984; Heckman, et al. 2010), the Abecedarian project (Ramey \& Campbell, 1984; Campbell et al., 2012), and Head Start (Zigler, 1979), "patterning" instruction in early elementary school (Pasnak, et al. 2015), and "Instrumental Enrichment" for adolescents (Feuerstein, Rand, Hoffman, \& Miller, 1980; Blagg, 1991). Some of these efforts have been based on extant theory (e.g, Weikart et al. 1971; Kidd et al., 2012)); others more eclectically on anything that seemed to the originators to be potentially useful (Gray \& Klaus, 1970). There have been both successes (Kidd et al. 2014) and failures (Blagg, 1991; Shriver, et al. 2017). Cognitive interventions vary tremendously in content; the common denominator is that they are efforts to improve thinking per se.

The following observations are intended to improve the ratio of success to failure, and to advance reasonable expectations of what can be achieved.

\subsection{Duration of Effects}

In the first place, those who conduct cognitive interventions may labor under a peculiar burden of unrealistic expectations. Procedures employed for a few months or perhaps a year or so, are too often expected to place the children who receive them in good stead for the rest of elementary school, or indeed, the whole of their education. That is extremely unlikely. Commonly, if the effects of an intervention disappear after a year or two, the intervention is considered to have failed. One might, more realistically, consider three possible outcomes. 


\subsubsection{Temporary Effects}

The effects of some interventions ARE temporary. Whatever was taught may be quickly forgotten or may be unemployable for some reason or may be unused even if remembered and employable. An example is a method for improving the speed of reading for high school students. It emphasizes moving your eyes down the center of the page with no regressions, instead of the line by line left to right progression almost everyone uses. The method works; if a student uses this technique reading is much faster, with decent comprehension. But it is an unnatural, uncomfortable way to read, and unless constantly monitored, children will just read the way they always read. So it is with cognitive interventions that teach unnatural ways of thinking. They are likely to be unemployed or forgotten. No educator wants that.

\subsubsection{Permanent Effects}

An intervention may be effective, employable, and in fact regularly employed, as long as the environment and need for it remain unchanged. For example, a cognitive intervention may be aimed at four-year-olds who lag behind their peers on cognitive development. It may indeed produce the formation of age-appropriate thinking abilities which are never lost. Those abilities may serve the needs of the four-year-olds very well at age four and even five. However, by the time one becomes six years old, more advanced abilities are needed, and those were never taught. The intervention produced changes in thinking abilities which have not been lost, but an intervention which will serve the children's needs in the world of six-year-olds is now needed.

The situation is similar to one that educators very often encounter. For example, third-graders who have not mastered third grade mathematics or reading may be retained for a year and given remedial instruction that, after that extra year, produces good mastery of third grade material. However, by the time they are in fifth or sixth grade they may be failing to master fifth or sixth grade material. It is not that the intervention did not have permanent results; they can still do the mathematics required of third graders, e.g. single digit multiplication, and still comprehend third grade reading material. But, the same old factors that got them behind before have gotten them behind again. What they mastered in their extra third grade year does not serve them well in grade six.

A nutritional intervention may be a fair example of what to expect from most cognitive interventions. A child who is starving in the Ogaden desert may be rescued and given the services of a nutritionist. As the nutritionist addresses the child's dietary needs, the child will become quite healthy. No one would doubt that the intervention worked. But send the child out into the desert again, and the child will starve again. Too many children who receive cognitive or other educational interventions are returned to deserts.

\subsubsection{Self-Propagating Effects}

We can always hope that, if a child is helped to master certain cognitive abilities, those will in turn enable the child to develop higher level abilities, and that those will lead to still higher level abilities, and so on until adulthood. For example, learning to both add and subtract COULD conceivably lead a child to develop, without further instruction, the concept of multiplication, and then division, and then algebra. Such self-propagating effects seem to be relatively rare, and education has to be a lengthy process. So is cognitive development. Yet self-propagation seems to be the expectation that government officials and the general public have for cognitive interventions. Educators seem to know better. Laying a good foundation doesn't mean that a house will build itself without further investment of effort. Likewise, producing abilities that provide a good foundation for the development of yet more advanced abilities doesn't mean that those will develop on their own.

\subsection{Who, When, and What}

\subsubsection{Who Is Most Likely to Profit From a Cognitive Intervention?}

The best targets for cognitive interventions are children who are currently functioning closer to the lower limit of their genetic potential. We need not have recourse to the nature-nurture debate to know that each has a role in cognitive development, whatever the proportion of their impacts. Every child functions within a range of abilities, whose ceiling and floor is determined by their biological inheritance. The human body is a good example. If we ate the right things, worked out enough, and got enough sleep we would be close to the ceiling of our physical potential. We would not have much room for improvement even after well-crafted interventions by nutritionists and physical trainers. If we ate like pigs, never lifted a finger, and stayed up most of the night as well as the day we might become so weak that we could hardly get up off the couch. And we would be ripe subjects for physical and nutritional interventions.

So it is with cognitive development. The best targets for cognitive interventions are probably children who have the most room to improve. Children who get little attention, live in poor environments with little stimulus or challenge, and are basically raised by a sister who is a few years older while their single parent works two fulltime jobs to stave off another eviction, will probably be functioning closer to their floor. It is the latter children, who are functioning closer to 
their natural floor, who have the most room to improve as the result of a cognitive intervention.

Children who get Gymboree, baby swimming lessons, are read to every night, are sent to very good schools, and are actively engaged in every stimulating and challenging activity their parents can think of, will probably be functioning close to whatever cognitive ceiling their genetics impart. They are therefore probably not good targets for cognitive interventions. This is not to say that children who are functioning at a very high level cognitively cannot be helped to function better yet. But they have cognitive abilities that serve them well, and may have already maximized those, or at least nearly maximized them.

Identifying just who a particular intervention can help is never easy. It is very easy to be over a child's head or under it, even if the child seems to be an apt target for a cognitive intervention. Pretesting helps, but is often not accurate enough, when young children are not familiar with the people testing them. For example, Pasnak, Hansbarger, Dodson, Hart, and Blaha (1996) conducted the same intervention simultaneously in two different schools which both served kindergartners whose achievement levels were low. The intervention worked very well in one school, with all children mastering all of the concepts they were taught, but did not work in the other school. Even after the intervention was continued for an extra month in the latter school, less than half of the children mastered all of the concepts taught; a third were still at ground zero. Such sample differences are likely to responsible for many failures to replicate the results of cognitive interventions.

\subsubsection{When Are Cognitive Interventions Most Likely to Be Profitable?}

Longitudinal research (Sonntag, Baker, Nelson , 1972; McCall, Applebaum, \& Hogarty, 1973) indicated long ago that intelligence is most likely to change at about age two years, at about ages four to seven years, and at ages $12-15$ years. These are, by an interesting coincidence, the times that Piaget quite independently observed that cognitions transition from one "stage" to another (Piaget, 1936, 1957). Neither Piaget nor the longitudinal researchers seem to have been aware of each other but the findings are provocative. Efforts to change cognition are probably most likely to succeed when cognitive development is already in flux. This is not to say that interventions cannot succeed at other ages, but researchers may profit from giving themselves the best chance.

Another aspect of "when" concerns the likelihood of some delay before new or improved cognitive abilities are likely to manifest themselves in a child's everyday performance. If, as is usually the case, the intervention is done during a school or preschool year, it unlikely that its fruits will show up immediately, except in direct tests of what was taught. Changes in academic or related performance will probably be delayed until the children have had substantial time to employ their new abilities. Better understanding of what their teachers, parents, and environment are teaching is likely to require some months of using and profiting from improved cognitive interpretations. In the school situation, this means that the intervention should take place as soon as possible in the fall, in hopes of improved academic performance by spring.

\subsubsection{What Kind of Cognitive Intervention Is Likely to Be Profitable?}

Interventions that teach thinking abilities that are natural are probably the most likely to succeed. In the first place, they ARE the types of thinking that children ordinarily develop and use, so there are no real barriers to prevent the child from employing them. Secondly, the environments and problems that children of the given age commonly encounter reinforce their use and practice. The only real problem has been that the children have been laggard in developing abilities that are suitable for their age and that would produce success in solving the challenges they encounter. Constant environmental reinforcement of age-appropriate thinking abilities will strengthen what the cognitive intervention has produced, if indeed natural ways of thinking have been taught.

\subsection{Simplicity as a Necessity}

In order for an intervention to have practical application, it must be easily understood and mastered by those who are going to use it to help children. An intervention that teachers or parents cannot employ without extensive or expensive instruction or supervision is not likely to be employed across the country (or world) even if it works. It must be simple enough that a workshop or (brief) instruction manual can convey what is to be done, even if the workshop or manual is not read carefully or remembered very well. Simplicity engenders success, complexity or subtlety leads to failure.

\subsection{Low Fidelity in Implementation}

"High fidelity" is currently a watch-word in studies supported by the federal government for research designed to lead to improvements in children's cognitive and academic functioning. The thought seems to be that failure to duplicate a procedure exactly enough is the likely reason for failure to replicate positive results obtained in a few schools when the same procedures are attempted in many schools. It is true that scientists, who usually are working with small effects, require high fidelity (exact replication of procedures) to determine what leads to what. But the fact is that to be useful outside the laboratory, any type of pedagogy must be successful with low fidelity. Teachers are likely to think that they 
bring something special to teaching and instructing their child or their classes. They are going to do it their way! An intervention must have so big an effect that it will produce results even when there is considerable variability in how it is applied to children. The inability to withstand low fidelity, and the effects of sample differences described earlier, are probably the main reasons that otherwise good cognitive interventions fail to be replicated on a large scale.

1.5 The Challenge.

The challenge for educators who wish to accelerate cognitive development is to determine just what cognitive abilities normally develop in children at any given age, if the children have normal nurturance and environments. If one knew that, one could, by employing some or all of the principles described in this essay, develop a successful cognitive intervention. Progress in answering this fundamental question is needed from both basic and applied researchers: what are the key thought processes employed by children at certain ages? If that question can be answered, the pragmatic steps outlined above can be profitably employed.

\section{Acknowledgment}

The preparation of this paper was supported by the Institute of Education Sciences, U.S. Department of Education, through Grant 305A170114 to George Mason University. The opinions expressed are those of the authors and do not represent views of the Institute or the U.S. Department of Education

\section{References}

Berrueta-Clement, J. R., Schweinhart, L. J., Barnett, W. S., Epstein, A. S., \& Weikart, D. P. (1984). Changed Lives: The effects of the Perry Preschool Program on youths through age 19. Monographs of the High/Scope Educational Research Foundation, 8. https://doi.org/10.1177/027112148500500204

Blagg, N. Can we teach intelligence? Lawrence Erlbaum Associates, Hillsdale, NJ.

Campbell, F. A. Pungiello, E. P., Kainz, K., Burchinal, M., Yi, P., Wasik, B. H., ... Ramey, C. T. (2012). Adult outcomes as a function of an early childhood educational program: An Abecedarian Project Follow-up. Developmental Psychology, (48), 1033-1043. https://doi.org/10.1037/a0026644

Feuerstein, R., Rand, Y., Hoffman, M. B., \& Miller, R. (1980). Instrumental enrichment: An intervention program for cognitive modifiability. Baltimore, MD. University Park Press.

Gray, S. W., \& Klaus, R. A. (1970). The Early Training Project: AQ seventh year report. Child Development, 41, 909-924. https://doi.org/10.2307/1127321

Heckman, J. J., Moon, S. H., Pinto, R, Savelyev, P. A., \& Yavitz, A, (2010). The Rate of Return to the High/Scope Perry Preschool Program. Journal of Public Economics, 94(1-2), 114-128. https://doi.org/10.1016/j.jpubeco.2009.11.001

Kidd, J. K., Curby, T. W., Boyer, C. E., Gadzichowski, K. M., Gallington, D. A. Machado, J. A., \& Pasnak, R. (2012). Benefits of interventions focused on oddity and seriation, $\mathrm{x}$ literacy, or numeracy. Early Education and Development, 23, 900-918. https://doi.org/10.1080/10409289.2011.621877

Kidd, J. K.,, Pasnak, R., Gadzichowski, K. M., Gallington, D. A., McKnight, P. E., Boyer, C. E., \& Carlson, A. (2014). Instructing first-grade children on patterning improves reading and mathematics. Early Education and Development, 25, 134-151. https://doi.org/10.1080/10409289.2013.794448

McCall, R. B., Applebaum, M. I., \& Hogarty, P. S. (1973). Developmental changes in mental performance. Monographs of the Society for Research in Child Development, 38(3, Serial No. 150). https://doi.org/10.2307/1165768

Pasnak, R., Hansbarger, A., Dodson, S., Hart, J., \& Blaha, J. (1996). Differential results of instruction at the preoperational - concrete operational transition. Psychology in the Schools, 33, 70-83. https://doi.org/10.1002/(SICI)1520-6807(199601)33:1<70::AID-PITS9>3.0.CO;2-\#

Pasnak, R., Kidd, J. K., Gadzichowski, K. M., Gallington, D. A., Schmerold, K. L., \& West, H. M. (2015). Abstracting sequences: Reasoning that is a key to academic achievement. Journal of Genetic Psychology, 176, 171-193. https://doi.org/10.15640/jehd.v8n2a4

Piaget, J. (1936). Origins of intelligence in the child. London: Routledge \& Kegan Paul

Piaget, J. (1957). Construction of reality in the child. London: Routledge \& Kegan Paul

Ramey, C. T., \& Campbell, F. A. (1984). Preventive education for high-risk children: Cognitive consequences of the Carolina Abecedarian Project. American Journal of Mental Deficiency, 88. 515-523.

Shriver, A., Lauderdale, L., Yassa, M., Schroeder, E., Chen, E., Schabinger, E., Righi, M., \& Pasnak, R. (2017). The effects of in-class tutoring of kindergarteners on patterning, reading, or mathematics. Journal of Education and 
Human Development, 6, 1-6. https://doi.org/10.15640/jehd.v6n1a1

Sonntag, L. W., Baker, C. T., \& Nelson, V. L. (1972). Mental growth and personality development: A longitudinal study. Monographs of the Society for Research in Child $x$ Development, 23(2, Serial No. 68). https://doi.org/10.2307/1165594

Weikart, D. P., Rogers, L., Adcock, C., \& McClelland, D. (1971). The cognitively oriented curriculum. Urbana, Ill; University of Illinois Press

Zigler, E. (1979). Project Head Start: Success or failure. In E. Ziglar \& J. Valentine, (Eds.) Project Head Start. NY: The Free Press.

\section{Copyrights}

Copyright for this article is retained by the author(s), with first publication rights granted to the journal.

This is an open-access article distributed under the terms and conditions of the Creative Commons Attribution license which permits unrestricted use, distribution, and reproduction in any medium, provided the original work is properly cited. 